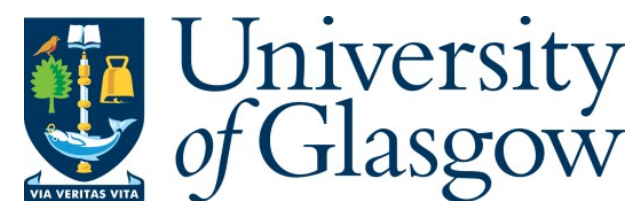

Wan Sulaiman, W.N., Caslake, M.J., Delles, C., Karlsson, H., Mulder, M.T., Graham, D., and Freeman, D.J. (2016) Does high-density lipoprotein protect vascular function in healthy pregnancy? Clinical Science, 130(7), pp. 491-497. (doi:10.1042/cs20150475)

This is the author's final accepted version.

There may be differences between this version and the published version. You are advised to consult the publisher's version if you wish to cite from it.

http://eprints.gla.ac.uk/118331/

Deposited on: 22 April 2016

Enlighten - Research publications by members of the University of Glasgow http://eprints.gla.ac.uk 


\title{
Does high density lipoprotein protect vascular function in healthy pregnancy?
}

\author{
Wan Sulaiman WN, Caslake M, Delles C, Karlsson H, Mulder M, Graham D, Freeman DJ.
}

\begin{abstract}
The maternal adaptation to pregnancy includes hyperlipidaemia, oxidative stress and chronic inflammation. In non-pregnant individuals these processes are usually associated with poor vascular function. However maternal vascular function is enhanced in pregnancy. It is not understood how this is achieved in the face of the adverse metabolic and inflammatory environment. Research into cardiovascular disease demonstrates that plasma high density lipoprotein (HDL), by merit of its functionality rather than its plasma concentration, exerts protective effects on the vascular endothelium. HDL has vaso-dilatory, anti-oxidant, anti-thrombotic and anti-inflammatory effects and can protect against endothelial cell damage. In pregnancy, plasma HDL concentration starts to rise at 10 weeks' gestation, peaking at 20 weeks. The initial rise in plasma HDL occurs around the time of the establishment of the feto-placental circulation, a time when the trophoblast plugs in the maternal spiral arteries are released generating oxidative stress. Thus there is the intriguing possibility that new HDL of improved function is synthesised around the time of the establishment of the feto-placental circulation. In obese pregnancy and to a greater extent in preeclampsia, plasma HDL levels are significantly decreased and maternal vascular function is reduced. Wire myography studies have shown an association between the plasma content of apolipoprotein Al, the major protein constituent of HDL, and blood vessel relaxation. These observations lead us to hypothesise that HDL concentration, and function, increases in pregnancy in order to protect the maternal vascular endothelium and that in preeclampsia this fails to occur.
\end{abstract}

\section{2 words}

\section{Introduction}

There is a large body of research concerning the role of plasma HDL as a protective agent against cardiovascular disease. This has come from a wide variety of epidemiological studies, human clinical studies and, particularly with respect to the molecular function of $\mathrm{HDL}$, from rodent animal models. However there is surprisingly little known about HDL in pregnancy. Research in humans remains limited to measurement of plasma concentration in healthy and complicated pregnancy whereas pregnant rodent models focus predominantly on metabolic programming of offspring rather than maternal adaptation to pregnancy. Here, the evidence for a role of HDL in maternal pregnancy in protecting vascular endothelium will be discussed incorporating the small amount of data available from human pregnancy and drawing parallels from the larger body of evidence, from humans and animals, in the wider cardiovascular field.

\section{Metabolic changes in healthy pregnancy}

The maternal adaptation to pregnancy involves significant metabolic change primarily to meet the demands of fetal growth and development (reviewed ${ }^{1}{ }^{1}$ ). In early pregnancy the mother becomes insulin sensitive in order to acquire adipose tissue required to supply fatty acids in later gestation. By the third trimester there is increased insulin resistance, hyperlipidaemia, increased inflammation and enhanced coagulation status. Oxidative stress increases with gestation as evidenced by an increase in markers of oxidative stress ${ }^{2}$. Insulin resistance in healthy pregnant women preserves the supply of glucose to support the growing fetus and supports lipolysis from maternal adipose tissue providing fatty acids for placental transport ${ }^{1}$. In later gestation, high fatty acid supply to the liver results in hypertriglyceridaemia as a consequence of increased very low density lipoprotein (VLDL) secretion. Plasma total cholesterol and low density lipoprotein (LDL) concentrations also increase 
but to a lesser extent ${ }^{1}$. Plasma high density lipoprotein (HDL) levels increase and reach their peak at mid gestation before declining in the last trimester ${ }^{3}$.

\section{Vascular function in pregnancy}

The metabolic and inflammatory changes described above would normally be associated with poor vascular function in non-pregnant individuals. High plasma lipid levels, in the presence of oxidative stress, leads to lipid peroxidation and production of reactive oxygen species (ROS) which are highly damaging to the vascular endothelium ${ }^{4}$. Gestational hypertriglyceridaemia also results in an increase in the production of highly atherogenic and easily oxidised small, dense LDL species ${ }^{1}$. However, pregnant women have enhanced vascular function. In healthy pregnancy, blood pressure progressively falls to reach a nadir at around 20 weeks mediated by a fall in maternal systemic vascular resistance due to vasodilation, followed by a gradual increase in blood pressure to reach pre-pregnancy levels. Studies looking at endothelium-dependent vascular function using flowmediated dilatation (FMD) of the brachial artery showed that pregnant women had a significantly higher increase in flow-mediated diameter than non-pregnant women, mediated at least in part by the endothelium-dependent vasodilator nitric oxide (NO) $)^{5}$. Flow-mediated dilatation progressively increased throughout gestation reaching a peak in the last trimester ${ }^{5}$. A positive correlation between percentage FMD and plasma triglyceride concentration confirms that pregnancy-related enhanced vascular function exists despite gestational hyperlipidaemia ${ }^{6}$. Microvascular function, both endothelium-dependent and endothelium-independent, determined using non-invasive laser Doppler imaging was also improved during gestation. ${ }^{7}$. Using wire myography, it has also been shown that small resistance arteries, isolated from healthy pregnant women, had better flowmediated relaxation than arteries from non-pregnant women ${ }^{8}$. It is not understood how improved vascular function is maintained in the face of a barrage of metabolic and inflammatory mediators normally associated with vascular damage. While the gestational period of nine months might appear to be a short time over which to influence vascular function by changes in the metabolite composition of plasma, there is an abundance of evidence showing that that the post-prandial increase in lipid concentration impairs vascular function in healthy individuals over a number of hours ${ }^{9}$.

One study has looked at maternal HDL and endothelium-dependent brachial artery flow-mediated dilatation (FMD) in healthy pregnancy ${ }^{6}$. A multivariate analysis found a positive association between \%FMD and plasma triglyceride, but no association with plasma HDL when both were entered into the model together. The authors interpreted this as the plasma triglyceride level reflecting the degree of maternal gestational adaptation driven by plasma estradiol levels and concluded that endothelial function improvement in pregnancy was likely due to the increased concentrations of HDL. It is difficult to interpret these data in light of the metabolic link between plasma triglyceride and $\mathrm{HDL}$ and the fact that plasma HDL concentration may not reflect HDL function (detailed later). Clearly more experimental data looking directly at the effects of HDL on vascular function are required.

\section{HDL has functions that protect the vascular endothelium}

HDL is a protein-rich and cholesteryl-ester rich lipoprotein complex and epidemiological studies show an inverse relationship between its plasma concentration and the risk of cardiovascular disease $^{10}$. Its major protein constituent is apolipoprotein Al (Apo Al). HDL was initially thought to exert all its anti-atherogenic effects via its key role in reverse cholesterol transport, whereby HDL removes cholesterol from peripheral tissues and delivers it to the liver for excretion. HDL mediates cholesterol efflux from cells involving several cellular mechanisms such as protein kinase $C$ activation, increasing CAMP concentration in macrophages and retroendocytosis ${ }^{11}$. However recent 
clinical trials of inhibitors of an enzyme intrinsic to HDL metabolism, cholesteryl ester transfer protein (CETP), have demonstrated that despite effective increases in HDL plasma concentration, the risk of cardiovascular disease was unaffected or even increased ${ }^{12}$. Numerous studies support the notion that CETP mediates reverse cholesterol transport ${ }^{13}$. By inhibiting CETP, reverse cholesterol transport may also be blocked demonstrating that increased HDL concentration may not be beneficial in every instance, especially if it reflects decreased turnover ${ }^{14}$. Such clinical data emphasise the importance of differentiating plasma HDL steady state concentration from HDL function. Recent research focus has shifted away from the benefits of high plasma concentrations of HDL towards the study of specific HDL functions mediated by the proteins and lipids associated with the HDL particle (Figure 1).

HDL enhances vasodilation of blood vessels at least in part by increasing the availability of NO. Endothelial NO is key for the regulation of vascular tone and structure. HDL regulates endothelial NO synthase (eNOS) expression ${ }^{15}$ and activity, stimulating NO production and inducing vasodilation ${ }^{16}$. An eNOS knockout mouse model confirmed the role of eNOS when the vasodilatory effect of HDL on aorta was lost in this animal ${ }^{17}$. Another study in scavenger receptor class B member 1 (SR-B1, a plasma membrane receptor for HDL) knockout mice using isolated HDL from pre- and postmenopausal women demonstrated that HDL-associated estradiol stimulates eNOS activity via the SR-B1 receptor ${ }^{18}$. The sphingosine-1-phosphate (S1P) receptor also has a role in mediating eNOS activation by $\mathrm{HDL}^{17}$. These protective effects of $\mathrm{HDL}$ on endothelium dependent vasodilatation through NO production are lost in cardiovascular disease patients ${ }^{19}$.

Other properties of HDL include antioxidant effects. HDL attenuates the oxidative stress produced by oxidised LDL and the smaller, denser subspecies of HDL have the most potent anti-oxidative effects $^{20}$. HDL carries enzymes that act as antioxidants such as paraoxonase-1 (PON-1) and platelet activating factor acetyl hydrolase (PAF-AH) ${ }^{21}$. In addition, integral HDL proteins such as apo Al can be sacrificed to oxidation to protect other molecules ${ }^{22}$. Reactive oxygen species (ROS) disrupt the active eNOS dimer and HDL can prevent oxidised LDL's inhibitory effect on eNOS. HDL prevents LDL oxidation through inactivation of lipid hydroperoxides mediated by $\mathrm{PON}-1^{23}$ and also via Apo Al which uses specific methionine residues to reduce peroxides into inactive lipid hydroxides ${ }^{24}$. HDL PON-1 content determines the capacity of HDL to stimulate NO production and protect the endothelium ${ }^{25}$. Plasma HDL concentrations are associated with a reduced risk of venous thrombosis ${ }^{26}$. SR-B1 knock out mice, which have high plasma HDL concentrations, have low platelet levels possibly due to an alteration in platelet structure resulting in increased clearance ${ }^{27}$. HDL can increase the anticoagulant activities of protein $\mathrm{S}$ and activated protein $\mathrm{C}$, an effect significantly reduced by anti-apo $\mathrm{Al}$ antibodies ${ }^{28}$. There is an inverse association between clot lysis time and plasma levels of $\mathrm{HDL}$ and apo Al which supports an anti-thrombotic role for $\mathrm{HDL}^{29}$.

HDL inhibits TNFa-induced endothelial expression of adhesion molecules (ICAM-1 and VCAM-1) in human umbilical endothelial cells ${ }^{30}$. HDL exerts its anti-inflammatory action through the SR-B1 receptor as siRNA against SR-B1 attenuated HDL's inhibitory effect on adhesion molecule expression $^{30}$. Lipopolysaccharide (LPS)-induced pro-inflammatory cytokines, such as TNF- $\alpha$, ICAM-1 and IL-6, were also reduced in THP-1 macrophages pre-treated with $\mathrm{HDL}^{31}$. Other anti-inflammatory effects of HDL and apo Al include inhibition of neutrophil activation, adhesion and infiltration ${ }^{32}$. HDL can protect against apoptosis of endothelial cells and damage the integrity of the endothelium monolayer ${ }^{33}$. HDL and apo Al can inhibit endothelial cell apoptosis mediated by oxidized LDL $^{34}$. Isolated HDL from healthy subjects was able to inhibit the apoptosis of endothelial cells in vitro and in contrast, HDL isolated from coronary artery disease patients exerted a pro-apoptotic effect ${ }^{35}$.

\section{Sphingosine-1-phospate and HDL}


Sphingosine-1-phosphate (S1P) is an HDL-associated lysophospholipid, anchored to the HDL particle via apolipoprotein $\mathrm{M}$, whose levels correlate directly with $\mathrm{HDL}$, apo Al and apo All levels ${ }^{36}$. Smaller, denser HDL is found to carry approximately twice the amount of S1P than that carried by larger HDL species $^{37}$. S1P is involved in many of HDL's biological effects including vasodilation, anti-oxidative actions and anti-inflammatory functions ${ }^{38}$. S1P is the major contributor to HDL-related effects on blood vessel relaxation, Akt activation and eNOS phosphorylation as these effects are totally abolished in S1P3 receptor deficient mice ${ }^{17}$. S1P also plays an important part in the anti-oxidative properties of HDL by protecting against the cytotoxic effects of oxidised $L^{2} L^{39}$. S1P's effects are complex and may act through different signaling pathways at different concentrations ${ }^{30}$.

\section{HDL and vascular function in pregnancy}

Plasma HDL concentrations increase throughout pregnancy ${ }^{3}$. Data from our laboratory, compiled using many samples collected at different gestations of pregnancy, shows a detailed profile of plasma HDL and triglyceride concentrations throughout pregnancy (Figure 2). Plasma triglyceride levels begin to increase substantially around 20 weeks' gestation and continue to rise until delivery. After delivery there is a sharp fall to slightly below pre-pregnancy levels and a rebound to prepregnancy levels by about 20 weeks post-partum. Plasma HDL concentration shows a different pattern. After an early slight decline in concentration, a rise in plasma HDL concentration is initiated at 10 weeks' gestation, peaking at a maximum level of $42 \%$ increased concentration at 20 weeks' gestation and declining to a plateau only $7 \%$ above early pregnancy levels by 30 weeks' gestation. The post-partum decline in HDL concentration is delayed until about 10 weeks after delivery and eventually pre-pregnancy levels are reached by 20 weeks after delivery.

The co-existence of high plasma HDL concentration, in the face of high plasma triglyceride concentration, is contrary to our metabolic understanding of the links between triglyceride and HDL metabolism in non-pregnant individuals. High plasma triglyceride in the non-pregnant population causes HDL and LDL to become enriched with triglyceride via the substrate-driven action of CETP. CETP facilitates the transfer of cholesteryl ester from HDL and LDL in exchange for triglyceride from VLDL. The resultant triglyceride rich-HDL is acted on by hepatic lipase leading to particle shrinkage and increased plasma HDL turnover thus linking high plasma triglyceride concentration with low plasma $\mathrm{HDL}^{40}$. Therefore in healthy pregnancy, high $\mathrm{HDL}$ concentration in the presence of high triglyceride concentration is unusual and this suggests that HDL metabolism becomes decoupled from triglyceride metabolism perhaps due to the estrogenic drive increasing HDL synthesis ${ }^{41}$. In addition, the timing of the increase in plasma HDL is interesting as concentrations begin to rise around the time of the establishment of the feto-placental circulation at 10-13 weeks' gestation. At this time trophoblast plugs in the maternal spiral arteries which protect embryonic tissue from oxidative damage are released generating oxidative stress. Thus there is the intriguing possibility that new HDL of improved function is synthesised around the time of the establishment of the fetoplacental circulation and prior to the increase in plasma triglyceride.

\section{Maternal vascular function and plasma HDL in obese pregnancy and preeclampsia}

While both non-obese and obese pregnant women have improved endothelium-dependent vascular function compared to the non-pregnant state, non-obese mothers have better endotheliumdependent microvascular function than obese mothers ${ }^{7}$. In addition, myometrial arteries isolated from pregnant women with high BMI $\left(>36 \mathrm{~kg} / \mathrm{m}^{2}\right)$ showed decreased relaxation to bradykinin compared to vessels obtained from pregnant women with non-obese BMI $\left(<30 \mathrm{~kg} / \mathrm{m}^{2}\right)^{42}$. Obese pregnancy is associated with metabolic syndrome in which plasma concentrations of triglyceride and VLDL are higher and concentrations of HDL lower than in non-obese pregnancy ${ }^{1,7}$. It is possible that in obese pregnancy, HDL concentrations may be insufficient to fully protect the maternal vascular 
endothelium and the obese pregnant woman is at higher risk of endothelial dysfunction increasing her risk for preeclampsia ${ }^{43}$.

Preeclampsia, a multi-system disorder particular to pregnancy, is a leading cause of maternal and neonatal morbidity and mortality and is one of the most difficult challenges facing obstetric medicine. The disease is characterised by widespread endothelial dysfunction, resulting in hypertension due to vasoconstriction, proteinuria attributable to glomerular damage and oedema secondary to increased vascular permeability. It complicates $2-8 \%$ of pregnancies, eludes early detection and there is no effective intervention other than iatrogenic delivery. In preeclampsia the maternal metabolic adaptation to pregnancy is abnormal with development of metabolic syndrome features including hypertriglyceridaemia and reduced $\mathrm{HDL}^{1}$. Low pre-conception plasma HDL [odds ratio (OR) $1.61(95 \% \mathrm{Cl} 1.29-2.01)]$ and high plasma triglycerides [OR $1.33(95 \% \mathrm{Cl} 1.09-1.63)]$ were independently associated with preeclampsia and/or gestational diabetes mellitus after adjustment for maternal confounders ${ }^{44}$. Furthermore, there was a significant $(P<0.001)$ interaction between low $\mathrm{HDL}$ and high triglycerides. A genetic predisposition to low plasma HDL is also associated with an increased risk of preeclampsia ${ }^{45}$. In preeclampsia there is increased lipid peroxidation, antioxidant levels are reduced ${ }^{46}$ and plasma PON-1 levels are decreased ${ }^{47}$. Maternal obesity, increased insulin resistance and aberrant fatty acid metabolism are involved in the pathogenesis of at least some phenotypes of preeclampsia ${ }^{48}$. Vascular dysfunction in preeclampsia has been observed both at the physiological level by a variety of techniques ${ }^{8,49,50}$ and in isolated blood vessels. In ex vivo wire myography studies, small resistance arteries derived from subcutaneous adipose tissue (representing systemic maternal vascular resistance) and myometrial biopsies (representing the vessels that supply the placenta) from preeclampsia pregnancy showed lower endotheliumdependent relaxation than vessels from healthy pregnancy ${ }^{51,52}$. NO-, EDHF- and eicosanoidmediated pathways were implicated. Preincubation of myometrial vessels from healthy pregnancy with plasma from women with preeclampsia, even if plasma was sampled at a gestation prior to the clinical manifestation of preeclampsia, inhibited endothelium-dependent relaxation ${ }^{53}$. Interestingly, an association between the concentration of the major protein constituent of $\mathrm{HDL}$, apo Al, in plasma and the vaso-relaxation was observed ${ }^{54}$. These effects are specific to gestational adaptive functions of the endothelium as no effects on vaso-relaxation were seen in non-pregnant vessels ${ }^{55}$.

\section{Hypothesis}

We hypothesise that establishment of the placental circulation triggers the formation of more and/or new, more effective, HDL as a pregnancy adaption that protects and enhances function of the vascular endothelium in the face of the oxidative, lipid and inflammatory stresses of healthy pregnancy. In healthy pregnancy, $\mathrm{HDL}$ is able to counter the oxidative and inflammatory stresses of the maternal adaptation to pregnancy. In preeclampsia, HDL fails to optimally adapt resulting in failure to protect the maternal endothelium resulting in vascular dysfunction.

\section{Future experimental work}

There are a number of questions regarding HDL in pregnancy that could be answered experimentally. Ex-vivo myography studies using vessels from pregnant animal models or in tissue from pregnant women can test whether HDL enhances vessel relaxation. Compositional studies including lipidomics and proteomics can test whether newly synthesised HDL in pregnancy differs from HDL in non-pregnant individuals. In vitro analysis of the vascular protective properties of HDL can demonstrate whether HDL from pregnant women has enhanced protective abilities as compared to $\mathrm{HDL}$ in the non-pregnant state. Comparison of HDL from women with preeclampsia with HDL from healthy pregnancies can test whether HDL gestational adaptive changes fail to take place in preeclampsia. 


\section{Clinical implications of a vascular protective role for HDL in pregnancy}

An understanding of the role of HDL in preeclampsia could inform clinical understanding and shape future management of the disease. The well-recognised athero-protective effects of HDL have led to the development of therapeutic agents to raise HDL concentration or increase HDL function for the prevention of cardiovascular disease. These agents include HDL infusing agents, recombinant LCAT, apo Al transcriptional upregulators and apo Al mimetic peptides ${ }^{56}$. Administration of synthetic HDL improves endothelial function in patients with hypercholesterolaemia ${ }^{57}$. Apo Al/phospholipid complexes and apo Al mimetics in CVD are in pre-clinical development ${ }^{58}$. Other studies showed HDL infusion was able to reduce atherogenic events including inflammation, thrombosis as well as apoptosis ${ }^{59}$. If $\mathrm{HDL}$ in pregnancy exerts vascular protective effects, then trials of synthetic HDL and apo Al mimetics in preventing/managing preeclampsia could be indicated. In pregnancy it is difficult to recommend interventions other than diet or lifestyle, for safety reasons. The HDL mimetics have enormous potential utility in pregnancy as they would be safe to administer and would allow manipulation of HDL function as well as concentration.

\section{2,812 words}




\section{References}

$1 \quad$ Huda SS, S.N., Freeman DJ. (2009) Lipoprotein metabolism and vascular complications in pregnancy. Clinical Lipidology 4, 91-102.

2 Loy, S.L., Kns, S. \& Jm, H.J. (2013) Increase in maternal adiposity and poor lipid profile is associated with oxidative stress markers during pregnancy. Prev Med 57 Suppl, S41-44.

3 Knopp, R.H., Warth, M.R., Charles, D., Childs, M., Li, J.R., Mabuchi, H. \& Van Allen, M.I. (1986) Lipoprotein metabolism in pregnancy, fat transport to the fetus, and the effects of diabetes. Biol Neonate 50, 297-317.

4 Gutierrez, J., Ballinger, S.W., Darley-Usmar, V.M. \& Landar, A. (2006) Free radicals, mitochondria, and oxidized lipids: the emerging role in signal transduction in vascular cells. Circ Res 99, 924-932.

5 Dorup, I., Skajaa, K. \& Sorensen, K.E. (1999) Normal pregnancy is associated with enhanced endothelium-dependent flow-mediated vasodilation. Am J Physiol 276, H821-825.

6 Saarelainen, H., Laitinen, T., Raitakari, O.T., Juonala, M., Heiskanen, N., Lyyra-Laitinen, T., Viikari, J.S., Vanninen, E. \& Heinonen, S. (2006) Pregnancy-related hyperlipidemia and endothelial function in healthy women. Circ $J$ 70, 768-772.

7 Stewart, F.M., Freeman, D.J., Ramsay, J.E., Greer, I.A., Caslake, M. \& Ferrell, W.R. (2007) Longitudinal assessment of maternal endothelial function and markers of inflammation and placental function throughout pregnancy in lean and obese mothers. J Clin Endocrinol Metab 92, 969-975.

8 Cockell, A.P. \& Poston, L. (1997) Flow-mediated vasodilatation is enhanced in normal pregnancy but reduced in preeclampsia. Hypertension 30, 247-251.

9 Mah, E. \& Bruno, R.S. (2012) Postprandial hyperglycemia on vascular endothelial function: mechanisms and consequences. Nutr Res 32, 727-740.

10 Gordon, T., Castelli, W.P., Hjortland, M.C., Kannel, W.B. \& Dawber, T.R. (1977) High density lipoprotein as a protective factor against coronary heart disease. The Framingham Study. Am J Med 62, 707-714.

11 von Eckardstein, A., Nofer, J.R. \& Assmann, G. (2001) High density lipoproteins and arteriosclerosis. Role of cholesterol efflux and reverse cholesterol transport. Arterioscler Thromb Vasc Biol 21, 13-27.

12 Barter, P.J., Caulfield, M., Eriksson, M., Grundy, S.M., Kastelein, J.J., Komajda, M., LopezSendon, J., Mosca, L., Tardif, J.C., Waters, D.D., Shear, C.L., Revkin, J.H., Buhr, K.A., Fisher, M.R., Tall, A.R. \& Brewer, B. (2007) Effects of torcetrapib in patients at high risk for coronary events. N Engl J Med 357, 2109-2122.

13 Tall, A.R. (1993) Plasma cholesteryl ester transfer protein. J Lipid Res 34, 1255-1274.

14 Barter, P.J. \& Rye, K.A. (2012) Cholesteryl ester transfer protein inhibition as a strategy to reduce cardiovascular risk. J Lipid Res 53, 1755-1766.

15 Kuvin, J.T., Ramet, M.E., Patel, A.R., Pandian, N.G., Mendelsohn, M.E. \& Karas, R.H. (2002) A novel mechanism for the beneficial vascular effects of high-density lipoprotein cholesterol: enhanced vasorelaxation and increased endothelial nitric oxide synthase expression. Am Heart J 144, 165-172.

16 Yuhanna, I.S., Zhu, Y., Cox, B.E., Hahner, L.D., Osborne-Lawrence, S., Lu, P., Marcel, Y.L., Anderson, R.G., Mendelsohn, M.E., Hobbs, H.H. \& Shaul, P.W. (2001) High-density lipoprotein binding to scavenger receptor-BI activates endothelial nitric oxide synthase. Nat Med 7, 853-857. 17 Nofer, J.R., van der Giet, M., Tolle, M., Wolinska, I., von Wnuck Lipinski, K., Baba, H.A., Tietge, U.J., Godecke, A., Ishii, I., Kleuser, B., Schafers, M., Fobker, M., Zidek, W., Assmann, G., Chun, J. \& Levkau, B. (2004) HDL induces NO-dependent vasorelaxation via the lysophospholipid receptor S1P3. J Clin Invest 113, 569-581.

18 Gong, M., Wilson, M., Kelly, T., Su, W., Dressman, J., Kincer, J., Matveev, S.V., Guo, L., Guerin, T., Li, X.A., Zhu, W., Uittenbogaard, A. \& Smart, E.J. (2003) HDL-associated estradiol 
stimulates endothelial NO synthase and vasodilation in an SR-BI-dependent manner. J Clin Invest 111, 1579-1587.

19 Gomaraschi, M., Ossoli, A., Favari, E., Adorni, M.P., Sinagra, G., Cattin, L., Veglia, F., Bernini, F., Franceschini, G. \& Calabresi, L. (2013) Inflammation impairs eNOS activation by HDL in patients with acute coronary syndrome. Cardiovasc Res 100, 36-43.

20 Sakuma, N., Yoshikawa, M., Hibino, T., Ohte, N., Kamiya, T., Kunimatsu, M., Kimura, G. \& Inoue, M. (2002) HDL3 exerts a more powerful antiperoxidative and protective effect against peroxidative modification of LDL than HDL2 does. J Nutr Sci Vitaminol (Tokyo) 48, 278-282.

21 Florentin, M., Liberopoulos, E.N., Wierzbicki, A.S. \& Mikhailidis, D.P. (2008) Multiple actions of high-density lipoprotein. Curr Opin Cardiol 23, 370-378.

22 Lu, N., Xie, S., Li, J., Tian, R. \& Peng, Y.Y. (2015) Myeloperoxidase-mediated oxidation targets serum apolipoprotein $\mathrm{A}-\mathrm{I}$ in diabetic patients and represents a potential mechanism leading to impaired anti-apoptotic activity of high density lipoprotein. Clin Chim Acta 441, 163-170.

23 Shekhanawar, M., Shekhanawar, S.M., Krisnaswamy, D., Indumati, V., Satishkumar, D., Vijay, V., Rajeshwari, T. \& Amareshwar, M. (2013) The role of 'paraoxonase-1 activity' as an antioxidant in coronary artery diseases. J Clin Diagn Res 7, 1284-1287.

24 Garner, B., Waldeck, A.R., Witting, P.K., Rye, K.A. \& Stocker, R. (1998) Oxidation of high density lipoproteins. II. Evidence for direct reduction of lipid hydroperoxides by methionine residues of apolipoproteins Al and All. J Biol Chem 273, 6088-6095.

25 Besler, C., Heinrich, K., Rohrer, L., Doerries, C., Riwanto, M., Shih, D.M., Chroni, A., Yonekawa, K., Stein, S., Schaefer, N., Mueller, M., Akhmedov, A., Daniil, G., Manes, C., Templin, C., Wyss, C., Maier, W., Tanner, F.C., Matter, C.M., Corti, R., Furlong, C., Lusis, A.J., von Eckardstein, A., Fogelman, A.M., Luscher, T.F. \& Landmesser, U. (2011) Mechanisms underlying adverse effects of HDL on eNOS-activating pathways in patients with coronary artery disease. J Clin Invest 121, 26932708.

26 Doggen, C.J., Smith, N.L., Lemaitre, R.N., Heckbert, S.R., Rosendaal, F.R. \& Psaty, B.M. (2004) Serum lipid levels and the risk of venous thrombosis. Arterioscler Thromb Vasc Biol 24, 1970-1975. 27 Dole, V.S., Matuskova, J., Vasile, E., Yesilaltay, A., Bergmeier, W., Bernimoulin, M., Wagner, D.D. \& Krieger, M. (2008) Thrombocytopenia and platelet abnormalities in high-density lipoprotein receptor-deficient mice. Arterioscler Thromb Vasc Biol 28, 1111-1116.

28 Fernandez, J.A., Deguchi, H., Banka, C.L., Witztum, J.L. \& Griffin, J.H. (2014) Re-Evaluation of the Anticoagulant Properties of High-Density Lipoprotein. Arterioscler Thromb Vasc Biol.

29 Zabczyk, M., Hondo, L., Krzek, M. \& Undas, A. (2013) High-density cholesterol and apolipoprotein $\mathrm{Al}$ as modifiers of plasma fibrin clot properties in apparently healthy individuals. Blood Coagul Fibrinolysis 24, 50-54.

30 Kimura, T., Tomura, H., Mogi, C., Kuwabara, A., Damirin, A., Ishizuka, T., Sekiguchi, A., Ishiwara, M., Im, D.S., Sato, K., Murakami, M. \& Okajima, F. (2006) Role of scavenger receptor class B type I and sphingosine 1-phosphate receptors in high density lipoprotein-induced inhibition of adhesion molecule expression in endothelial cells. J Biol Chem 281, 37457-37467.

31 Song, G.J., Kim, S.M., Park, K.H., Kim, J., Choi, I. \& Cho, K.H. (2015) SR-BI mediates high density lipoprotein (HDL)-induced anti-inflammatory effect in macrophages. Biochem Biophys Res Commun 457, 112-118.

32 Murphy, A.J., Woollard, K.J., Suhartoyo, A., Stirzaker, R.A., Shaw, J., Sviridov, D. \& ChinDusting, J.P. (2011) Neutrophil activation is attenuated by high-density lipoprotein and apolipoprotein A-I in in vitro and in vivo models of inflammation. Arterioscler Thromb Vasc Biol 31, 1333-1341.

33 Mineo, C., Deguchi, H., Griffin, J.H. \& Shaul, P.W. (2006) Endothelial and antithrombotic actions of HDL. Circ Res 98, 1352-1364.

34 Suc, I., Escargueil-Blanc, I., Troly, M., Salvayre, R. \& Negre-Salvayre, A. (1997) HDL and ApoA prevent cell death of endothelial cells induced by oxidized LDL. Arterioscler Thromb Vasc Biol 17, 2158-2166. 
35 Riwanto, M., Rohrer, L., Roschitzki, B., Besler, C., Mocharla, P., Mueller, M., Perisa, D., Heinrich, K., Altwegg, L., von Eckardstein, A., Luscher, T.F. \& Landmesser, U. (2013) Altered activation of endothelial anti- and proapoptotic pathways by high-density lipoprotein from patients with coronary artery disease: role of high-density lipoprotein-proteome remodeling. Circulation 127, 891-904.

36 Zhang, B., Tomura, H., Kuwabara, A., Kimura, T., Miura, S., Noda, K., Okajima, F. \& Saku, K. (2005) Correlation of high density lipoprotein (HDL)-associated sphingosine 1-phosphate with serum levels of HDL-cholesterol and apolipoproteins. Atherosclerosis 178, 199-205.

37 Kontush, A., Therond, P., Zerrad, A., Couturier, M., Negre-Salvayre, A., de Souza, J.A., Chantepie, S. \& Chapman, M.J. (2007) Preferential sphingosine-1-phosphate enrichment and sphingomyelin depletion are key features of small dense HDL3 particles: relevance to antiapoptotic and antioxidative activities. Arterioscler Thromb Vasc Biol 27, 1843-1849.

38 Sattler, K. \& Levkau, B. (2009) Sphingosine-1-phosphate as a mediator of high-density lipoprotein effects in cardiovascular protection. Cardiovasc Res 82, 201-211.

39 Kimura, T., Sato, K., Kuwabara, A., Tomura, H., Ishiwara, M., Kobayashi, I., Ui, M. \& Okajima, F. (2001) Sphingosine 1-phosphate may be a major component of plasma lipoproteins responsible for the cytoprotective actions in human umbilical vein endothelial cells. J Biol Chem 276, 3178031785.

40 Thuren, T. (2000) Hepatic lipase and HDL metabolism. Curr Opin Lipidol 11, 277-283.

41 Barton, M. (2013) Cholesterol and atherosclerosis: modulation by oestrogen. Curr Opin Lipidol 24, 214-220.

42 Myers, J., Hall, C., Wareing, M., Gillham, J. \& Baker, P. (2006) The effect of maternal characteristics on endothelial-dependent relaxation of myometrial arteries. Eur J Obstet Gynecol Reprod Biol 124, 158-163.

43 Bodnar, L.M., Ness, R.B., Harger, G.F. \& Roberts, J.M. (2005) Inflammation and triglycerides partially mediate the effect of prepregnancy body mass index on the risk of preeclampsia. Am J Epidemiol 162, 1198-1206.

44 Baumfeld, Y., Novack, L., Wiznitzer, A., Sheiner, E., Henkin, Y., Sherf, M. \& Novack, V. (2015) Pre-Conception Dyslipidemia Is Associated with Development of Preeclampsia and Gestational Diabetes Mellitus. PLoS One 10, e0139164.

45 Spracklen, C.N., Saftlas, A.F., Triche, E.W., Bjonnes, A., Keating, B., Saxena, R., Breheny, P.J., Dewan, A.T., Robinson, J.G., Hoh, J. \& Ryckman, K.K. (2015) Genetic Predisposition to Dyslipidemia and Risk of Preeclampsia. Am J Hypertens 28, 915-923.

46 Patil, S.B., Kodliwadmath, M.V. \& Kodliwadmath, M. (2009) Lipid peroxidation and antioxidant activity in complicated pregnancies. Clin Exp Obstet Gynecol 36, 110-112.

47 Kumru, S., Aydin, S., Gursu, M.F. \& Ozcan, Z. (2004) Changes of serum paraoxonase (an HDLcholesterol-associated lipophilic antioxidant) and arylesterase activities in severe preeclamptic women. Eur J Obstet Gynecol Reprod Biol 114, 177-181.

48 Sattar, N., Gaw, A., Packard, C.J. \& Greer, I.A. (1996) Potential pathogenic roles of aberrant lipoprotein and fatty acid metabolism in pre-eclampsia. Br J Obstet Gynaecol 103, 614-620.

49 Blaauw, J., Graaff, R., van Pampus, M.G., van Doormaal, J.J., Smit, A.J., Rakhorst, G. \& Aarnoudse, J.G. (2005) Abnormal endothelium-dependent microvascular reactivity in recently preeclamptic women. Obstet Gynecol 105, 626-632.

50 Franz, M.B., Burgmann, M., Neubauer, A., Zeisler, H., Sanani, R., Gottsauner-Wolf, M., Schiessl, B. \& Andreas, M. (2013) Augmentation index and pulse wave velocity in normotensive and preeclamptic pregnancies. Acta Obstet Gynecol Scand.

51 Ashworth, J.R., Baker, P.N., Warren, A.Y. \& Johnson, I.R. (1999) Mechanisms of endotheliumdependent relaxation in myometrial resistance vessels and their alteration in preeclampsia.

Hypertens Pregnancy 18, 57-71.

52 Knock, G.A. \& Poston, L. (1996) Bradykinin-mediated relaxation of isolated maternal resistance arteries in normal pregnancy and preeclampsia. Am J Obstet Gynecol 175, 1668-1674. 
53 Hayman, R., Warren, A., Brockelsby, J., Johnson, I. \& Baker, P. (2000) Plasma from women with pre-eclampsia induces an in vitro alteration in the endothelium-dependent behaviour of myometrial resistance arteries. BJOG 107, 108-115.

54 Hayman, R.G., Sattar, N., Warren, A.Y., Greer, I., Johnson, I.R. \& Baker, P.N. (1999)

Relationship between myometrial resistance artery behavior and circulating lipid composition. Am J Obstet Gynecol 180, 381-386.

55 Hayman, R., Warren, A., Johnson, I. \& Baker, P. (2001) Inducible change in the behavior of resistance arteries from circulating factor in preeclampsia: an effect specific to myometrial vessels from pregnant women. Am J Obstet Gynecol 184, 420-426.

56 Kingwell, B.A., Chapman, M.J., Kontush, A. \& Miller, N.E. (2014) HDL-targeted therapies: progress, failures and future. Nat Rev Drug Discov 13, 445-464.

57 Spieker, L.E., Sudano, I., Hurlimann, D., Lerch, P.G., Lang, M.G., Binggeli, C., Corti, R., Ruschitzka, F., Luscher, T.F. \& Noll, G. (2002) High-density lipoprotein restores endothelial function in hypercholesterolemic men. Circulation 105, 1399-1402.

58 Reddy, S.T., Navab, M., Anantharamaiah, G.M. \& Fogelman, A.M. (2014) Apolipoprotein A-I mimetics. Curr Opin Lipidol 25, 304-308.

59 Kingwell, B.A. \& Chapman, M.J. (2013) Future of high-density lipoprotein infusion therapies: potential for clinical management of vascular disease. Circulation 128, 1112-1121. 
Figure 1. HDL protective actions at the endothelium. A number of the constituents of HDL may interact with the vascular endothelium. Production of nitric oxide (NO) induces blood vessel dilation. The main apolipoprotein on HDL, apoAl, may increase NO production via AMP-activated protein kinase (AMPK) signalling. Sphingosine-1-phosphate (S1P) is a lipid anchored to the HDL particle via the apolipoprotein apoM, and it can interact with $\mathrm{S}_{1} \mathrm{P}_{1}$ and $\mathrm{S}_{1} \mathrm{P}_{3}$ receptors on the vascular endothelial cell leading to increased endothelial nitric oxide synthase (eNOS) activity, partly via AMPK pathways. HDL also carries the antioxidant enzyme paraoxonase-1 (PON-1). This enzyme, possibly in addition to other anti-oxidative effects of HDL, inhibits the oxidation of LDL to form oxidised LDL (OxLDL). PON-1 also can inhibit OxLDL receptor (LOX-1) activity thus reducing the production of reactive oxygen species (ROS) via NAHPH oxidase, and preventing the inhibitory effects of ROS on eNOS.

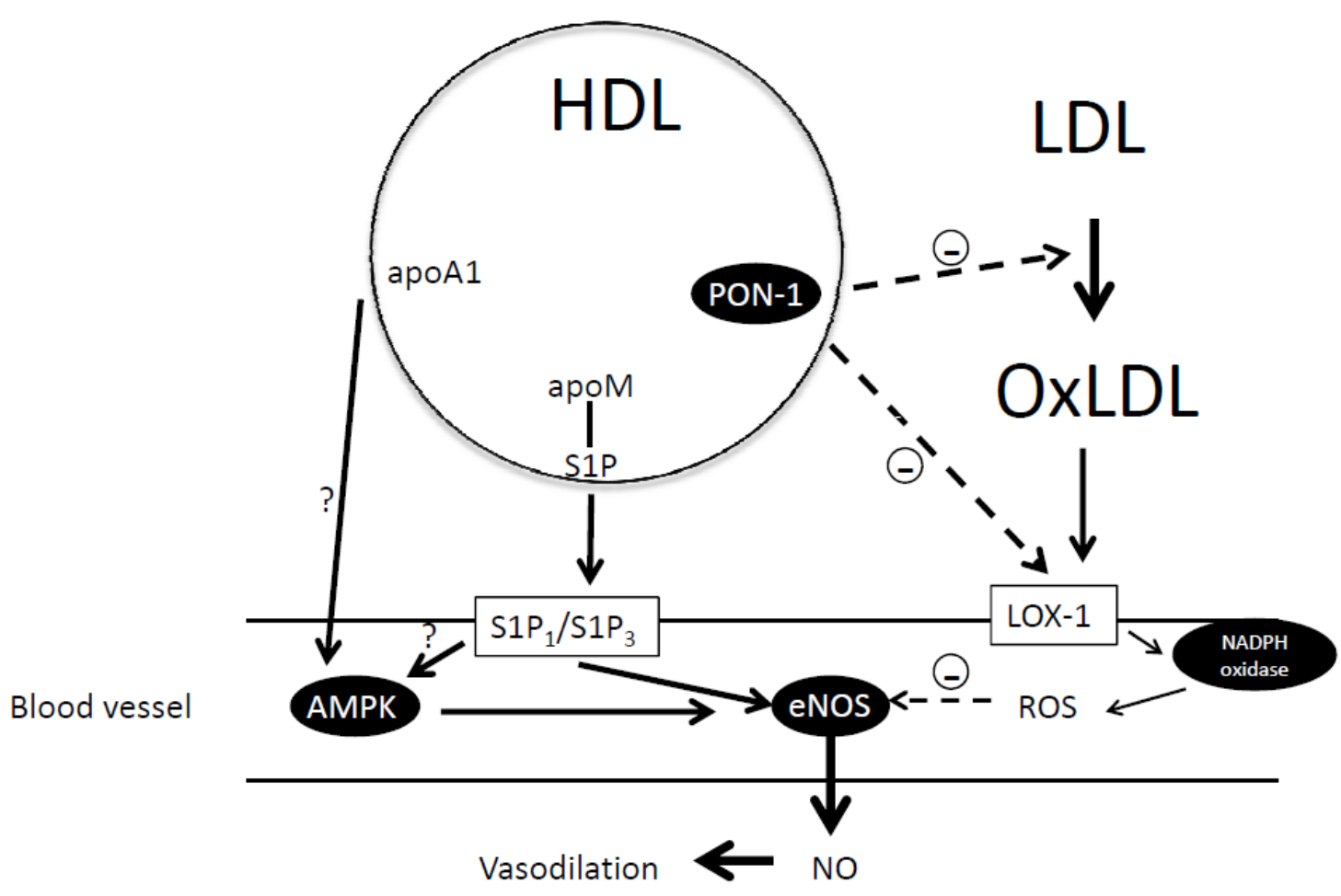


Figure 2 Maternal plasma HDL-cholesterol and plasma triglyceride concentrations during pregnancy and post partum. Unpublished data from a series of overlapping longitudinal and crosssectional studies in our laboratory. Lipid measurements were carried out by Vascular Biochemistry, University of Glasgow a Centre for Disease Control (CDC) UK laboratory for the Lipid Standardisation Programme (cholesterol, triglyceride, HDL-C) and the CDC Reference Laboratory for cholesterol and HDL-C, thus lipid measurements are standardised over time.

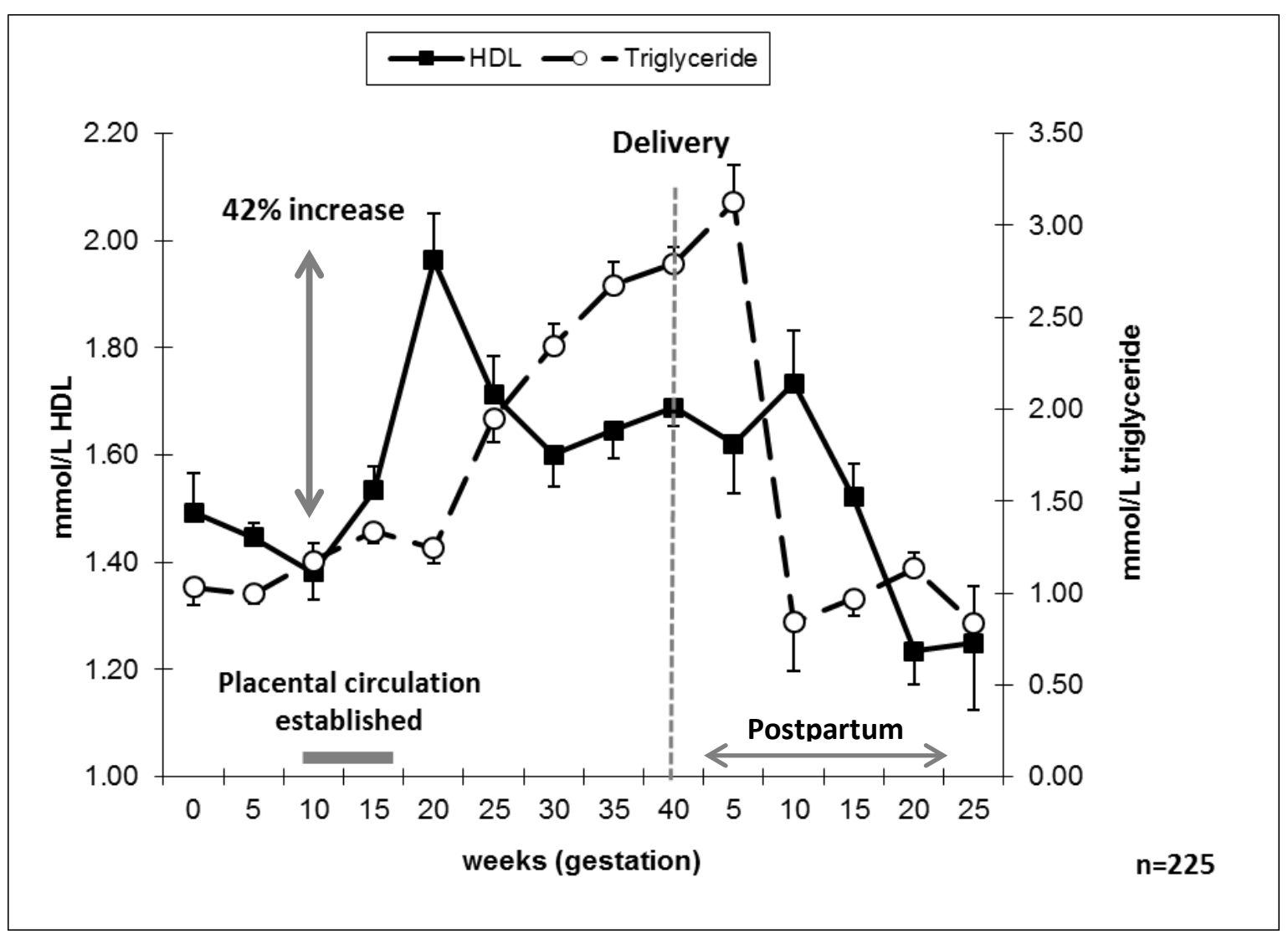

